Paideusis

\title{
Some Problems About Racism, Sexism, Etc.
}

\section{John Wilson}

Volume 4, Number 2, 1991

URI: https://id.erudit.org/iderudit/1073381ar

DOI: https://doi.org/10.7202/1073381ar

See table of contents

Publisher(s)

Canadian Philosophy of Education Society

ISSN

0838-4517 (print)

1916-0348 (digital)

Explore this journal

Cite this article

Wilson, J. (1991). Some Problems About Racism, Sexism, Etc. Paideusis, 4(2),

27-32. https://doi.org/10.7202/1073381ar

This document is protected by copyright law. Use of the services of Érudit (including reproduction) is subject to its terms and conditions, which can be viewed online.

https://apropos.erudit.org/en/users/policy-on-use/
This article is disseminated and preserved by Érudit.

Érudit is a non-profit inter-university consortium of the Université de Montréal, Université Laval, and the Université du Québec à Montréal. Its mission is to promote and disseminate research.

https://www.erudit.org/en/ 


\section{Some Problems About Racism, Sexism, Etc.}

\section{John Wilson, Department of Educational Studies, Oxford University}

I have to include the untidy "etc." in my title because, despite the longrunning preference for fastening on race and sex, there are currently many other candidates. ' $\mathrm{Ag}(\mathrm{e})$ ism', for example, has a special appeal for me as an aging philosopher. However, there are many others to be found in teachers' guidebooks -- 'regionalism', 'classism', and so forth. ${ }^{1}$ I propose to raise some problems which apply to all such "-isms." It is worth saying in advance that, in my experience at least of the educational world, these problems are not normally given much attention. They are neglected either by those many people who prefer to join a crusade, or else by those (equally numerous but perhaps less vocal) who acquiesce in the status quo. But they are important problems. Even if we cannot solve them without further conceptual reflection and, no doubt, more empirical evidence, we at least need to take them on board.

\section{Target Groups}

The first problem is raised by my "etc." By what criteria are we to target particular groups as oppressed or in need of particular attention? We have an infinity of candidates, since there is an infinite number of human differences. Shall we choose the old, the young, the poor, the physically disabled, the Black, the fat, the stupid, the ugly? It is possible to think that the criteria often used have to do with (a) the public visibility of the targets (colour is more visible than stupidity), (b) their social salience (there are race riots, but not usually riots in which the more stupid fight with the more intelligent), (c) the extent to which certain groups resent, or are thought to resent, their oppression, and (d) the extent to which the groups have formed themselves into political pressuregroups ("black power" or whatever).

None of these seems to me sensible criteria in the light of pure reason, though they may be inevitable at the political level. ${ }^{2}$ If we stepped back from political pressures and were concerned purely with justice, what criteria might be used?

There might be two such criteria. The first would have to do with just how much oppression really existed against what groups. Certainly the answer to this would not always be clear. However, sometimes it would as, for example, with the Jews in Nazi Germany. You cannot get much more oppressive than that! We need a view about whether it is worse to be treated as physically ugly and disgusting, or as in some way inferior because a woman, or as deficient because physically handicapped, or mentally incompetent, or poor, etc. These questions are not wholly unanswerable, and some of the answers might surprise us if we conducted enough empirical enquiries by means of interviews. The second criterion would have to do with our particular interests and intentions. If, for instance, we were thinking of legislation against oppression, then we should have to consider what was practicable. It would, for example, be harder to legislate against oppression or injustice to the fat and ugly than against injustice to Blacks or women. If, on the other hand, we were interested in educational courses about personal relationships without any question of making laws or even rules, then we might want to stress less obvious and more subjective differences. 
There would also be a tactical or pedagogical question about whether one should really target particular groups at all. One might argue that the really important thing is to give pupils a firm grasp of the general principles at stake here -- roughly, that one should not use irrelevant reasons for distributing advantages to people, or that we are all in some sense equally important in the eyes of God, etc. Perhaps targeting particular groups distracts attention from such principles which, if firmly grasped, will see the individual through any and every case of intolerance or prejudice. A philosopher might want to say just "When you give a reason, 'because he's X' (Black, male, fat, ugly, etc.), make sure that the "because' makes sense." It must at least be right to show that particular groups and reasons are examples of this general principle, even if one wanted to stress particular examples at particular times. Otherwise, the message just comes across as "Don't be nasty to Blacks (women, etc.)" which, however admirable, is not the point.

\section{Descriptive Ambiguities}

"Isms" rely on the idea that some people stand in a particular relationship (R) to a particular group (G) and it is obviously important that both $R$ and $G$ should be clearly described. Usually we rest content with a single description -say, "racial prejudice." The G here is "race" but, as is notorious, it is not at all clear just what that means. Are the English, for example, one race, or a mixture of many? How do we distinguish races from nations? Are we to accept ethnologists' terminology -- "Caucasian," "Negroid," etc.? How many races are there in the Caribbean? and so on. The relationship, R, is also unclear. Some people are just ignorant about $G$, while others are prejudiced. Others are simply allergic, while some others just hate $G$, or are frightened of G. Part of the problem here is conceptual: we need to think harder about $R$ in particular. How do we distinguish ignorance from prejudice, and prejudice from sheer hatred? Do these presumably different things combine in some way? Also, part of the problem is empirical. We need much more research to discover just what various individuals actually feel and think, just what their $R$ is to various Gs. "Racial prejudice" is a name for nothing clear.

The obscurity is compounded by the combination of $\mathrm{R}$ with $\mathrm{G}$. A person reacts to, say, Blacks in a way which strikes us prima facie as unreasonable. ${ }^{3}$ But is he prejudiced against their colour, or frightened of their culture, or allergic to their ethnic origins, or what? Unless we can get some sort of grip on what possibilities are real ones, we cannot even describe properly what it is that we are trying to cure. We shall not know whether education is the answer, or depth psychotherapy, or even whether there are genetically-acquired features in some people which cannot be dealt with by either.

Of course, I have picked a deliberately difficult example. But even where a G can be clearly identified -- for instance, "women" -- it will still not be clear under what description the $\mathrm{R}$ operates. What is it about women that the person hates or fears or resents? Their beauty? Their power? Their sexuality? How far are these feelings conscious or unconscious? Of course, we may -- perhaps should -- make laws forbidding prejudicial decisions (in offering jobs, for instance) against women. Though this may up to a point do more justice to women, it will not cure, or re-educate, men. To do that, we have to know just what disease they suffer from. 


\section{Ignorance of Difference or Similarity}

This problem is extremely obvious, yet its force for practice seems to be largely neglected. "Because he/she is a woman/Black/British/pygmy, etc." has logical force -- indeed, is only intelligible -- as a reason only in virtue of some relevant feature common to or characteristic of these Gs. But the fact is that we just do not know about many features that are commonly referred to. Of course, assumptions are made with all the confidence that should belong to knowledge. In the past, there were wide differences between G-members and others and in the present, there are few or no differences relevant to different treatment. One is amazed, for instance, that any serious person should claim anything like certainty over the question of whether there are or are not basic, non-negotiable differences between the psychologies of either sex. Similarly, it is not immediately obvious, to say the least, that the English as a race are just as gifted as, say, the French, Germans, and Italians in the arts of cooking, or music, or the visual arts. These matters are doubtful.

It is no help to say that justice can be done to these Gs if it is not founded on something like secure knowledge. Certainly, no G-member need be positively prevented, by law or social convention, from pursuing or enjoying any good. But, thereafter, justice consists ('doing justice to' is a useful phrase to remember here) in respecting the actual nature and features of G-members. 'Equality' in the sense of 'sameness' will not serve us. Even the notion of equal opportunity, as I have argued elsewhere, ${ }^{4}$ does not help, since having an opportunity depends on having a certain power or ability. Nor is it any use to suppose that alleged differences are the result purely of social conditioning. First, such conditioning may itself be irreversible -- the differences remain and have to be catered for. Second, we still do not know whether social conditioning just creates such differences rather than merely reinforcing differences that exist already.

Almost everyone, it seems, works on some sort of conscious or unconscious theory about the nature of different races, sexes, or other groups. Perhaps that is inevitable since we have to make practical decisions on some basis or other. But the history of such theories is hardly an encouraging one, and there is no reason to suppose that contemporary theories which assume more or less total similarity of both aptitude and attitude (an important distinction) will fare any better. It is as difficult now to find research money to investigate non-negotiable differences between G-members and others as it was a hundred years ago since, in both cases, everyone thinks they know the answer already. All of this is intensely depressing, but worth remembering.

\section{Public and Private Domains}

I come now to a much more complex area, where much of the difficulty consists of getting clear about just what the problems are. One might begin, however, by trying to draw some sort of distinction between (a) public domains, in which there could reasonably be some sort of uniform rule or law about the treatment of G-members, and (b) private domains, in which this would not be reasonable. To take two extreme cases: (a) it seems reasonable to have laws which do not disqualify people from voting because they are Black or female or 
Catholic, etc., but (b) it seems unreasonable to have laws forbidding the formation of private groups which do not admit people because they are White or male or Protestant, etc. We have the vague idea that there is (a) a public domain which deals with public goods and rights, such as the right to vote, or receive education, or medical treatment, or food rations if food is in short supply; and (b) a private one, in which we decentralise powers of decision so that people can form and organise their clubs, families, marriages, and so on as they wish.

The main difficulty here is that we do not seem able to operate any simple and objective criterion of relevance in such matters, partly because it is not always clear just what would count as relevant, and partly because (even if it were clear) there would still be a problem about who should be allowed to decide this. An example will make this clearer. Suppose I use only my own money to organize some sort of small club, or research group, or even a business. Suppose further that I exclude from this various G-members, on the grounds that they are white, or unattractive, or fat, or stupid, or Catholic. Then a critic might say, "Look here, some of these exclusions at least are unreasonable, because their G-membership is not relevant to your purposes. Fat people can do well in helping to run a business, white people can also do research, and why only have attractive people in your club or entourage?" I reply, "But these features are relevant to my purposes, which are not purely instrumental. I just do not want an ambience with these people in it, any more than I want to marry them. Why should I not be allowed to make what rules I like?" Then the critic can reply, "But even if these features are, as it were, relevant to you, they are not really relevant. It is not reasonable to want only pretty faces in your office, or to react against white ones, or to be repelled by fat people." I reply (and this reflects our two difficulties), "(1) In personal or semi-personal relationships (and these are certainly part of our enterprise), surely the tastes of those setting up the enterprise are relevant, even if they are ultimately unreasonable. Maybe I should be a better person if $I$ found brunettes and fat people attractive as well as blondes and thin ones, but the fact is that I do not -- and I can't do much about that, perhaps not even after a lengthy course of psychotherapy. (2) Even granted irrelevancy, am I not to have the political right to be unreasonable in my own way by setting up this group?"'

In so replying, I raise, not now the question of what can be demonstrated as relevant or irrelevant though that, as we have just seen, is hard enough. But I do raise question of who should have the right to decide. The matter is really one about decentralisation of decision-making. Take another example: most of us think (1) that marriages in which all important matters are decided by the man, in which only the man's sexuality is catered for, and in which the man has most of the economic power, are far from ideal -- even if the woman freely acquiesces in such a marriage, or indeed thinks it to be right and proper. We might also think (2) that if two people freely contract for such a marriage, however unreasonable, then that is their business and we should not force them to do otherwise. Compare this also to the well-known case of the sadomasochist duo: it is not, perhaps, an ideally reasonable form of sexual interaction, but it should not be politically prohibited so long as the partners do not harm other people.

Note that we cannot even press too hard the idea of "harm to others." That is not the point here. Suppose that men are likely to spend much more 
money and attention on a comparatively small class of women who are highly attractive, and much less on the unattractive. Suppose further, if feminists will allow it, that receiving money, attention, offers of marriage, and so on is desirable. Then, in a clear sense, this male preference disadvantages unattractive women. But nobody, I hope, will want to say that male attentions should, therefore, be rationed so that all women receive a fair share not because of the administrative difficulties in enforcing this, but rather because we recognize that the whole practice of sexual interaction does not lend itself to such moves. If by some version of the Pol Pot regime, we try to achieve this sort of justice to the under- privileged, we thereby destroy the whole business of personal relationships. ${ }^{5}$

Some form of personal relationships does, in fact, enter into many parts of our lives. Voting may be a clear case of the public domain, and marriage of the private, but if we consider such institutions as small businesses, schools, clubs, churches, local communities, and the like, the difficulty of drawing a clear line is obvious, and cannot be solved by a naive appeal to relevance. Normally, we hope to settle such things by allowing space and opportunity for different groups to have their own private institutions (on the analogy of different churches); but what shall we say if a whole society -- that is, a sovereign state -- sees itself in this way? Characteristically, many societies have so seen themselves, and excluded various types of people (Jews, the unskilled, Blacks, etc). Is this reasonable or not?

It is crucial here to distinguish, as I have tried to do above, between the questions (1) whether it is reasonable for a particular society to do this (to which the answer may be a resounding "No"; the exclusion of Jews, for instance, may be greatly impoverishing to a society, and (2) whether or not we subscribe to a rule empowering societies to do this even if it is not in their best interests (let alone the interests of G-members). It is hard to imagine any form of international relations which did not characteristically subscribe to such a principle (though in certain cases, notably South Africa, many people waver) because the only alternative would be a rule allowing any country to use some kind of force on any other on the grounds (reasonable or not) that the latter was being unjustly exclusive. This alternative seems unacceptable. We seem driven to the conclusion that not only private individuals and groups, but whole societies, have to be allowed to set up what rules they like -- even if we wish to persuade (not force) them to have rules which are based on pure reason rather than prejudice against G-members.

In none of the above do I wish to produce any definite answers or conclusions. Obviously much more needs to be said about all the problems I have mentioned. Can anything sensible be said, in the meanwhile, about what sort of action we should take (or refrain from taking) in the light of these difficulties?

It will not do, of course, to suggest that no action should be taken until we are entirely clear about all of them. It is no good waiting for all the philosophers' and psychologists' cows to come home since they never do. In particular, there seems no reason to retain rules which positively debar any G-members from seeking public advantages or enjoying public rights. For we can do this without targeting particular Gs, and without knowing just what differences (if any) exist between G-members and others; and we can make up our own minds about what is to count as 'public'. Thereafter, it seems to me 
that we should go easy on making anti-racist (anti-sexist, etc.) rules or enforcements, but go hard on education. For enforcements imply that we already know what the right answers to these problems actually are. That we know, for instance, that women are so similar in their desires and attitudes to men that they ought to be equally represented in doing science, or in certain professions, or that we can confidently identify just which groups ought to be targeted, or that the integration of G-members with non-G-members is always and everywhere desirable. But we do not know these things. Education, on the other hand, cannot by its nature indoctrinate pupils with 'right answers' to these or any other problems. But it can help pupils to modify their behaviour and their feelings in the light of reason. If I am right in supposing that these problems are rarely raised in educational contexts -- I mean, with the pupils themselves, then we shall simply move from one ideology to another. That is ultimately to no one's advantage.

\section{Notes}

${ }^{1}$ Not, interestingly, 'religionism', although one might have thought that religious intolerance was as obvious a target as any. Is this just because 'religionism' sounds too absurd?

${ }^{2}$ I mean that there might be a group which sees itself as deeply oppressed has a powerful organization, and will cause a good deal of trouble in society if it is not attended to -- never mind whether its views and demands are justified. Then a sensible government might, however reluctantly, have to yield to its demands. Thus, in recent history there is a question about whether followers of Islam do well to react with violence against certain books or practices. But there is also a political question about whether we should give way to them, at least to some extent, in order to keep blood off the streets. These questions are different.

${ }^{3}$ Even this may be jumping the gun since it is not so much unreasonable of me not to find, say, brunettes attractive. Reason does not come into it; it is just a pity.

${ }^{4} \mathrm{~J}$. Wilson, "Does Equality of Opportunity Make Sense?" Journal of the Philosophy of Education, 24, 1990.

${ }^{5}$ Problems about what rules to make under the heading of sexual harassment run into the same difficulties. 